\title{
Assessment of Neuropharmacological Activity of Methanol Extract of Leaves of Nerium oleander (Family: Apocynaceae)
}

\author{
Sharmin Sultana ${ }^{1 *}$, Md. Lokman Hossain ${ }^{2}$ \\ ${ }^{1}$ Pharmacy Discipline, Life Science School, Khulna University, Khulna-9208, Bangladesh \\ ${ }^{2}$ Department of Pharmacy, Stamford University Bangladesh, Dhaka-1217, Bangladesh
}

DOI: $10.36348 /$ sjmps.2020.v06i02.001

| Received: 27.01.2020 | Accepted: 03.02.2020 | Published: 07.02.2020

*Corresponding author: Sharmin Sultana

\section{Abstract}

The current study evaluated the sedative and anxiolytic activity of methanol extract of Nerium oleander (Family: Apocynaceae) leaves alongside with its phytochemical screening. Preliminary phytochemical screening revealed the presence of reducing sugar, tannin, glycoside, flavonoids, alkaloids, gum and protien. The methanol extract of Nerium oleander (MENO) was evaluated for sedative activity using the mice model open field test and hole cross test. The effect of MENO on central nervous system (CNS) for anxiolytic activity was determined by light/dark Box, elevated plus maze test and whole board test using swiss albino mice as experimental animal. The MENO showed significant ( $\mathrm{p}<0.05$ ) sedative effect at the doses of 200 and $400 \mathrm{mg} / \mathrm{kg}$ body weight in Open field test and Hole cross test. The present study demonstrated that MENO showed significant $(\mathrm{p}<0.05)$ anxiolytic effect at the doses of 200 and $400 \mathrm{mg} / \mathrm{kg}$ body weight in light-dark box test and elevated plus maze test. The movement of mice decreased significantly in hole-board test after the administration of MENO at doses of 200 and $400 \mathrm{mg} / \mathrm{kg}$ body weight, which indicates the potential anxiolytic activity. The present study indicates that the MENO possesses sedative and anxiolytic activity which trend to justify its use as traditional medicine. So, the plant may be further subjected to chemical investigation to isolate and purify the bioactive compound(s) responsible for its pharmacological activity.

Keywords: Nerium oleander, Hole Cross test, Open Field Test, Elevated plus maze test, Light-Dark box test, Hole-board test.

Copyright @ 2020: This is an open-access article distributed under the terms of the Creative Commons Attribution license which permits unrestricted use, distribution, and reproduction in any medium for non-commercial use (NonCommercial, or CC-BY-NC) provided the original author and source are credited.

\section{INTRODUCTION}

Nerium oleander belongs to the family of Apocynaceae commonly known as rose bay, raktakarabi, kaner. It is a very poisonous plant and evergreen shrub with thin, erect branches; it can grow to a height of 4-8 metres. It is a strong, multipurpose plant that produces eye-catching summertime flowers in white, red, pink, salon, and light yellow. The leaf sizes vary due to sunlight conditions and the time it was produced. Larger leaves are seen under more cloudy conditions instead of under a more sunshine habitat, and this varies between the varieties [1]. The leaves and flowers are sedative, cardiotonic, diaphoretic, diuretic, emetic, expectorant and sternutatory. A decoction of the leaves has been applied externally in the treatment of scabies and parasitic skin worms and to reduce swellings. The root has powerful resolving capacity. Because of its poisonous nature, it is only used externally. Oil obtained from the root is used for the management of leprosy and skin diseases. The whole plant is said to have anticancer properties [2,3]. The plant is also used as a rat poison, a parasiticide and an insecticide. The crushed leaves and bark can be as insecticide. The leaves contain small amounts of latex that can be used to make rubber, though the amount is too small for commercial utilization [4]. As part of our ongoing research, here we evaluated the neuropharmacological activity of leaves of Nerium oleander.

\section{Materials ANd Methods}

\section{Sample collection and extraction}

The leaves of Nerium oleander were collected from Khulna, Bangladesh and identified by the experts of Bangladesh National Herbarium, Mirpur, and Dhaka. At first, the adulterants were removed and then shade dried. The dried samples were grounded to coarse powder and $700 \mathrm{gm}$ powder was taken in a clean, round bottomed flask (5 liters) and soaked in 3.5 liter of Methanol (95\%). Then, it was sealed by cotton plug and aluminum foil and kept for a period of 15 days accompanying occasional shaking and stirring. The 
whole mixture was then filtered through cotton followed by Whatman No.1 filter paper and the filtrate thus obtained was concentrated by rotary evaporation. Then the filtrate was air dried.

\section{Collection and Maintenance of Animals}

Swiss-Albino mice of both sex (age of 4-5 weeks) were used for the experiment. They were collected from the animal breeding house of Jahangirnagar University, Savar, Dhaka, Bangladesh. After collection, mice were kept in standard environmental condition (temperature: $\left(24.0 \pm 1.0{ }^{\circ} \mathrm{C}\right)$, relative humidity: $55-65 \%$ and $12 \mathrm{hrs}$ light/12 hrs dark cycle) and fed International Center for Diarrhoeal Disease Research, Bangladesh (ICDDR, B) formulated food and water. The animals were kept for at least 3-4 days in the laboratory before the test.

\section{Drugs and Chemicals}

The standard drugs Diazepam was collected from Incepta Pharmaceuticals Ltd. Dhaka, Bangladesh. Saline water which was used for dilution purpose was obtained from Opsonin Pharma Limited.

\section{Phytochemical tests}

The crude extract was subjected to preliminary phytochemical screening for the detection of major functional groups followed by pharmacological screening [5].

\section{Determination of Sedative activity}

Depressive disorder is a widespread psychiatric disorder affecting about $21 \%$ of the world's population. The presently using drugs can impose a variety of side-effects including cardiac toxicity, hyperpiesia, sexual dysfunction, body weight gain, and sleep disorder. There is an increasing interest in the beneficial effects of natural products on mental disorders throughout the last decade.

\section{Open field test}

The Open Field Test (OFT) is clearly the most frequently used of all behavioral tests in pharmacology and neuroscience. Despite the simplicity of the apparatus, however, open field behavior is complex. Consequently, it has been used to study a variety of behavioral traits, including general motor function, exploratory activity and anxiety-related behaviors. Animals were divided into control, positive control, and test groups comprising five mice in each group. The test groups received methanol extract of Nerium oleander at the doses of 200 and $400 \mathrm{mg} / \mathrm{kg}$ body weight orally whereas the control group received vehicle (Saline water; $0.1 \mathrm{~mL} / \mathrm{mice}$ ). Animals in positive control group received diazepam (1 $\mathrm{mg} / \mathrm{kg}$ b.w.). The open field instrument was cleaned after each test session to prevent the next mouse from being influenced by the odors deposited in the urine and feces of the previous mouse. The number of squares visited by the animals was counted for $5 \mathrm{~min}$ at $0,30,60,90$, and $120 \mathrm{~min}$ after oral administration of MENO and the standard [6].

\section{Hole cross test}

This study was to characterize the emotional behavior of mice using the hole-board test. The animals were divided into four groups (control, positive control, and two test groups) having five mice in each group. The test groups received the leaves parts of methanol extract of Nerium oleander doses level of 200 and 400 $\mathrm{mg} / \mathrm{kg}$ body weight orally whereas the vehicle control and positive control groups received vehicle (0.1 $\mathrm{mL} /$ mice saline water) and the standard drug Diazepam ( $1 \mathrm{mg} / \mathrm{kg}$ b.w.), respectively. The number of passage of a mouse through the hole from one chamber to other was counted for a period of $5 \mathrm{~min}$ at $0,30,60,90$ and $120 \mathrm{~min}$ after oral administration of the test drugs and the standard [6].

\section{Determination Anxiolytic activity}

Drugs acting on the central nervous system (CNS) were first discovered by primitive humans and are still the most widely used group of pharmacologic agents CNS Action [7]. The effects of drugs on CNS with reference to the neurotransmitters for specific circuits, attenuation should be developed to general organizational principles of neurons. It requires explicit delineation of the sites at which given neurotransmitters may operate and the degree of specificity with which such site that may be affected [8].

\section{Elevated plus-maze test}

The elevated plus-maze (EPM) test consisted of two open arms $(30 \times 5 \times 0.25 \mathrm{~cm})$ and two closed arms $(30 \times 5 \times 15 \mathrm{~cm})$ emanating from a common central platform $(5 \times 5 \mathrm{~cm}$. The entire apparatus was raised to a height of $40 \mathrm{~cm}$ above ground level. At the beginning of the session, a mouse was placed at the center of the maze, its head facing an open arm and allowed to explore the maze for 5 minutes and the time spent and number of entries in each type of arms was recorded. The plus maze was meticulously cleaned after each test. The mice were divided into four groups ( 5 mice/group). The control group received vehicle (saline water 0.1 $\mathrm{mL} / \mathrm{mice})$. Diazepam ( $1 \mathrm{mg} / \mathrm{kg}$ b.w., IP) was used as the positive control or standard group and MENO extract at the doses of 200 and $400 \mathrm{mg} / \mathrm{kg}$ b.w., orally, in the two remaining groups. After each trial, the EPM apparatus was wiped clean with alcohol (70\%) Solution [9].

\section{Light-Dark Box test}

The apparatus $(45 \times 21 \times 21 \mathrm{~cm})$ consisted of two compartments with one third painted white and two thirds painted black, and these compartments were separated by a divider with a $3.5 \times 3.5 \mathrm{~cm}$ opening at floor level. The small compartment was highlighted black and illuminated by a red light $(60 \mathrm{~W} ; 4 \mathrm{~lx})$, whereas the large compartment was made white and luminously illuminated with a 60-W (400 lx) light 
source. The compartments were prepared with infrared beam sensors (four in the white area, three in the black area). Each mouse was tested by placing it in the center of the white area, facing away from the dark one, and was allowed to explore the novel environment for $5 \mathrm{~min}$ and thereby enabling the detection of locomotion in each zone, time spent in each zone, latency of the first crossing from one compartment to the other and shuttle crossings between both compartments. This test exploited the conflict between the animal's tendency to explore a new environment and its fear of bright light $[10,11]$. The mice were divided into four groups (5mice/group). Diazepam was used as the positive control or standard group and MENO was given at doses of 200 and $400 \mathrm{mg} / \mathrm{kg} \mathrm{b}$. w., orally, in two remaining groups.

\section{Hole-Board test}

The hole-board apparatus consists of a gray wooden box $(40 \times 40 \mathrm{~cm}, 2.2 \mathrm{~cm}$ thick $)$ with 16 equidistant holes with $3 \mathrm{~cm}$ in diameter. Each animal was placed singly in the center of the board opposite the observer and the number of head dipping into the hole was recorded over a 5 min exploration period on the board. Head dipping was recorded only when both eyes disappeared into the hole [12]. The mice were divided into four groups (5 mice/group). Diazepam was used as the positive control or standard and MENO was given at doses of 200 and $400 \mathrm{mg} / \mathrm{kg}$ body weight, orally, in the two remaining groups.

\section{Statistical ANALYSIS}

Results were expressed as mean \pm S.E.M. Variance was analyzed using One-way Analysis of Variance (ANOVA). $\mathrm{P}<0.05$ was measured to be statistically significant.

\section{RESUltS}

In the preliminary phytochemical screening the extract showed the presence of reducing sugar, tannin, glycoside, flavonoids, alkaloids, gum and protien.

\section{Sedative activity test Open field test}

In the open field test, the number of squares traveled by the mice was suppressed significantly from its initial score by MENO at the doses level of 200 and $400 \mathrm{mg} / \mathrm{kg}$ body weight which was comparable to the reference drug diazepam (Table 1).

Table-1: Effect of MENO in Open Field Test on Mice

\begin{tabular}{|c|c|c|c|c|c|c|}
\hline Treatment & Dose, Route & 0 min & $30 \mathrm{~min}$ & $60 \mathrm{~min}$ & $90 \mathrm{~min}$ & 120 min \\
\hline Control & $0.1 \mathrm{~mL}$, oral & $108.2 \pm 1.01$ & $108.2 \pm 0.92$ & $100.4 \pm 0.50$ & $99.8 \pm 1.01$ & $98.2 \pm 2.13$ \\
\hline Diazepam & $1 \mathrm{mg} / \mathrm{kg}$, i.p. & $106.5 \pm 0.92$ & $14.3 \pm 0.74 *$ & $9.8 \pm 0.92 *$ & $6.7 \pm 0.37 *$ & $14.2 \pm 0.37 *$ \\
\hline MENO & $200 \mathrm{mg} / \mathrm{kg} \mathrm{b.w}$ & $108.3 \pm 1.14$ & $41.5 \pm 0.83 *$ & $30.4 \pm 0.6^{*}$ & $22.1 \pm 1.04 *$ & $17.2 \pm 0.66^{*}$ \\
\hline MENO & $400 \mathrm{mg} / \mathrm{kg}$ b.w. & $109.6 \pm 0.70$ & $35.4 \pm 0.37 *$ & $19.2 \pm 0.66^{*}$ & $18.5 \pm 0.94 *$ & $16.8 \pm 0.50 *$ \\
\hline
\end{tabular}

\section{Hole cross test}

MENO exhibited significant decrease of movement compare with control group at the doses of
200 and $400 \mathrm{mg} / \mathrm{kg}$ body weight (Table 2). The maximum decrease of movement was observed at 90 and $120 \mathrm{~min}$.

Table-2: Effect of MENO in Whole Cross Test on Mice

\begin{tabular}{|c|c|c|c|c|c|c|}
\hline Treatment & Dose, Route & 0 min & 30 min & 60 min & 90 min & 120 min \\
\hline Control & $0.1 \mathrm{~mL}$, oral & $61.2 \pm 1.16$ & $59.0 \pm 0.94$ & $60.3 \pm 0.40$ & $57.0 \pm .044$ & $53.4 \pm 1.50$ \\
\hline Diazepam & $1 \mathrm{mg} / \mathrm{kg}$, i.p. & $61.8 \pm 0.86$ & $48.0 \pm 0.70^{*}$ & $24.6 \pm 1.02^{*}$ & $17.8 \pm 0.96^{*}$ & $14.0 \pm 0.4^{*}$ \\
\hline MENO & $200 \mathrm{mg} / \mathrm{kg}$ b.w & $62.0 \pm 1.09$ & $52.3 \pm 0.67^{*}$ & $33.3 \pm 0.6^{*}$ & $24.2 \pm 1.15^{*}$ & $20.7 \pm 3.14^{*}$ \\
\hline MENO & $400 \mathrm{mg} / \mathrm{kg}$ b.w. & $62.5 \pm 0.60$ & $41.2 \pm 1.01^{*}$ & $20.4 \pm 0.97^{*}$ & $19.1 \pm 1.02^{*}$ & $17.4 \pm 1.07^{*}$ \\
\hline
\end{tabular}

Values are expressed as Mean \pm SEM $(n=5)$;

$* \mathrm{P}<0.05$ compared with the control group (Dunnett's Test)

\section{Anxiolytic Activity test \\ Elevated plus Maze test}

In EPM, treating mice with MENO increased the percentage of time spent in open arm at the doses of 200 and $400 \mathrm{mg} / \mathrm{kg}$ body weight compared to control group. In addition, diazepam (1 $\mathrm{mg} / \mathrm{kg} \quad$ b. w.) significantly increased the percentage of time spent in the open arms in the EPM. Conversely, the number of entries and the time spent in the closed arms were reduced (Table 3). 
Table-3: Effect of MENO on mice in spent time in open and closed arm

\begin{tabular}{|c|c|c|c|}
\hline Treatment & Dose $(\mathbf{m g} / \mathbf{k g}$ b.w.) & Time in open $\mathbf{~ a r m ~}(\mathbf{s e c})$ & Time in closed arm $(\mathbf{s e c})$ \\
\hline Control & $0.1 \mathrm{~mL} / \mathrm{mice}$ & $12.8 \pm 0.89$ & $251.7 \pm 0.89$ \\
\hline Standard & $1 \mathrm{mg} / \mathrm{kg}$ & $47.8 \pm 1.019^{*}$ & $247.4 \pm 1.019^{*}$ \\
\hline MENO & $200 \mathrm{mg} / \mathrm{kg}$ & $30.1 \pm 0.50^{*}$ & $263.4 \pm 0.50^{*}$ \\
\hline MENO & $400 \mathrm{mg} / \mathrm{kg}$ & $71.4 \pm 0.87^{*}$ & $230.6 \pm 0.88^{*}$ \\
\hline
\end{tabular}

Values are expressed as Mean $\pm \operatorname{SEM}(n=5)$;

$* \mathrm{P}<0.05$ compared with the control group (Dunnett's Test)

\section{Light-Dark Box test}

In LDB, treating mice with MENO increased the percentage of time spent in light area at the doses of
200 and $400 \mathrm{mg} / \mathrm{kg}$ body weight compared to control group (Table 4).

Table-4: Effect of MENO on mice in spent time in light and dark area

\begin{tabular}{|c|c|c|c|}
\hline Treatment & Dose (mg/kg b.w.) & Time in light area (sec) & Time in dark area (sec) \\
\hline Control & $0.1 \mathrm{~mL} / \mathrm{mice}$ & $63.6 \pm 0.67$ & $263.4 \pm 0.68$ \\
\hline Standard & $1 \mathrm{mg} / \mathrm{kg}$ & $253.4 \pm 2.22^{*}$ & $46.6 \pm 2.22^{*}$ \\
\hline MENO & $200 \mathrm{mg} / \mathrm{kg}$ & $96.0 \pm 1.58^{*}$ & $204.0 \pm 1.57 *$ \\
\hline MENO & $400 \mathrm{mg} / \mathrm{kg}$ & $125.2 \pm 3.56^{*}$ & $174.8 \pm 3.57 *$ \\
\hline \multicolumn{4}{|c|}{ Values are expressed as Mean \pm SEM (n=5); } \\
& $* \mathrm{P}<0.05$ compared with the control group (Dunnett's Test)
\end{tabular}

\section{Hole-Board test}

In the whole board test, treatment with MENO decreased the number of head dipping at the doses of
200 and $400 \mathrm{mg} / \mathrm{kg}$ body weight in comparison to control group (Table 5).

Table-5: Effect of MENO on mice in hole-board test

\begin{tabular}{|c|c|c|}
\hline Treatment & Dose and Route & No. of Head Dipping into hole \\
\hline Control & $0.1 \mathrm{~mL}$, Oral & $52.2 \pm 1.46$ \\
\hline Standard & $1 \mathrm{mg} / \mathrm{kg}$, i.p. & $25.0 \pm 1.58^{*}$ \\
\hline MENO & $200 \mathrm{mg} / \mathrm{kg}$, Oral & $55.5 \pm 1.02^{*}$ \\
\hline MENO & $400 \mathrm{mg} / \mathrm{kg}$, Oral & $41.7 \pm 1.36^{*}$ \\
$* \mathrm{P}<0.05$ compared with the control group (Dunnett's Test)
\end{tabular}

\section{DISCUSSION}

The most important step in evaluating drug action on the CNS is to observe the net reduction of excitatory synaptic transmission of the test animals. Anxiolytics (e.g. diazepam) are known to exert their pharmacological action by increasing the gamma aminobutyric acid (GABA) content of mice cerebral hemisphere [13]. Numerous studies have shown that GABAergic and serotonergic neurotransmission are involved in etiology, expression and treatment of anxiety. Benzodiazepines (BZDs), barbiturates, Tricyclic antidepressants (TCA's) have been used for long time to treat anxiety disorders. The serious side effects related with these drugs, such as rebound insomnia, sedation, muscle relaxation, withdrawal and tolerance (BZD's, barbiturates and alcohol), sexual dysfunction, anticholinergic, antihistaminic effects (TCA's) have limited their use in patients. Buspirone, the non-sedative anxiolytic agent is ineffective in a high percentage of patients. It is also associated with tachycardia, palpitation, gastric discomfort and so on [14].
In this work, we studied the central effects of Nerium oleander leaves on swiss albino mice. The most vital findings was an anti-depressive effect as revealed by the open field test and hole cross test and anxiolytic effect by the elevated plus maze, light-dark box and hole-board test. This study shows that oral administration of MENO elicits a potent and dosedependent sedative and anxiolytic effect. Oral administration of MENO suggestively inhibited the movement of mice suggesting that the central nervous system activity in mice both on open field and hole cross method that indicates sedative activity. In EPM test, if the MENO had anxiolytic effect, the time spent in open arm would rise gradually and time spent in closed arm would decrease gradually and our experimental data showed that having of anxiolytic properties of MENO. In LDB, The delayed latency of mice in light area designates anxiolytic properties of MENO like the benzodiazepine group drug involves the binding with GABA receptor. If the MENO had anxiolytic effect, the time spent in light area would rise gradually and time spent in dark area would decrease progressively. The whole cross and open field test are the most common experimental models used to 
investigate the exploratory behavior of the animals. The sedative effects of Nerium oleander leaves in open field test and whole cross test were prominent at all doses level when compared to control group $(0.9 \%$ saline water) in a dose dependent manner. The significant $(\mathrm{p}<0.05)$ sedative effects at doses of 200 and $400 \mathrm{mg} / \mathrm{kg}$ body weight could be due to strong and effective concentration of the active constituent. It is well established that several drugs like benzodiazepines suppress curiosity of the animals about a new environment resulting in a decrease in their locomotor activity [15]. Likewise, our results demonstrated that MENO significantly $(\mathrm{p}<0.05)$ reduced locomotion of the animals both in hole cross and in open field tests. Locomotors activity is considered as an index of alertness and a decrease in that indicates sedative effect [16]. The suppressive effect was observed from $0 \mathrm{~min}$ and continued up to $120 \mathrm{~min}$ in MENO administration. Saponins are known to show amphetamine antagonism and sedative property and decrease spontaneous motor activity in the experimental animal models. It has been reported that the presence of glycosides, and flavonoids in plant extract possess sedative and anxiolytic effect through the interaction with GABA receptors [17]. Bearing in mind our results and previously published reports, it can be said that the aforementioned chemical components in the extract might contribute to the observed pharmacological activities. We may, therefore, conceive that the methanol extract of Nerium oleander contains psychoactive principles that are sedative and anxiolytic in nature. The elevated plus maze is a widely used behavioral model in mice and has been validated to investigate the anxiolytic potential of different pharmacological agents [18]. The open arm activities of the animals in EPM reflect a conflict between the mice innate behavior to keep itself in a protected area (e.g., closed arms) and motivation to explore in a novel environment, where the anxiolytic agents induce the exploratory activities of the mice in the open arm [19]. If the MENO had anxiolytic effect, the time spent in open arm would rise gradually and time spent in closed arm would decrease gradually. It was found that the experimental data showed similar scenario (Table 3). So, the effects of mice with MENO on time spent in open and time spent in close arm were significant, which indicates of having possibility of anxiolytic properties of MENO. Light dark box method is a widely used technique for screening the anxiolytic or anxiogenic effect of natural products. It based on the innate aversion of mice to brightly illuminated areas and the spontaneous exploratory behavior of mice in response to mild stressors [20]. It has been reported that simple measurement of time spent in the light area, but not the number of transfers, is the most consistent and useful parameter for assessing an anxiolytic action [20]. If the MENO had anxiolytic effect, the time spent in light area would rise gradually and time spent in dark area would decrease gradually. Our finding was similar as shown in table 4 . So, the effects of treatment of mice with MENO on time spent in light and time spent in dark area were statistically significant, which is an indication of anxiolytic properties of MENO. The present data demonstrated that in the hole-board test, the number of head-dips by the mice treated with MENO was comparable at the doses of 200 and 400 $\mathrm{mg} / \mathrm{kg}$ body weight with diazepam treated group. The administration of MENO also decreased the number of head dipping at doses of 200 and $400 \mathrm{mg} / \mathrm{kg}$ body weight which indicates the anxiolytic properties of MENO.

\section{CONCLUSION}

The present study demonstrates that the methanol extract of Nerium oleander has sedative and anxiolytic activity. Our findings can be correlated to the traditional uses of this plant to treat various CNS related ailments. However, further studies are needed to isolate the pharmacologically active compound(s) responsible for these activities.

\section{ACKNOWLEDGEMENT}

The authors are grateful to the Laboratory of Pharmacgnosy and Pharmacolgy, Department of Pharmacy, Stamford University Bangladesh, Dhaka for providing all supports to carryout of this research

\section{REFERENCES}

1. The Plant List: A Working List of All Plant Species". Retrieved 13 April 2014.

2. Duke, J. A., \& Ayensu, E. S. Medicinal Plants of China Reference Publications 1985.

3. Chiej, R. (1984). Encyclopaedia of medicinal plants. MacDonald. Orbis.

4. Vines, R. A. (1982). Trees of north Texas (Vol. 14). University of Texas Press.

5. Hossain, M. L., Monjur-Al-Hossain, A. S. M., \& Sadhu, S. K. (2016). HPLC Profiling and Evaluation of In-vitro Antioxidant Activity of Cirsium arvense L. (Family: Asteraceae). Journal of Pharmacognosy and Phytochemistry, 5(1), 272.

6. Basak, A., Hossain, M. L., \& Parvin, M. N. (2016). Evaluation of phytochemical and pharmacological activities of Bacopa monnieri (L.). Int J Sci Rep, 2(10), 242.

7. Katznung, B.G. (1998). In Basic and Clinical Pharmacology. International Edition. McGraHill Companies, 343

8. Bloom, F.E. (1996). In Goodman and Gilman's the Pharmacological Basis of Therapeutics, (Editors: Hardman JG and Limbird LE), pp. 277-278, $9^{\text {th }}$ International Edition.

9. Almeida, E. R. D., Rafael, K. R. D. O., Couto, G. B. L., \& Ishigami, A. B. M. (2009). Anxiolytic and anticonvulsant effects on mice of flavonoids, linalool, and $\alpha$-tocopherol presents in the extract of leaves of Cissus sicyoides L.(Vitaceae). BioMed Research International, 2009. 
10. HascoëT, M., \& Bourin, M. (1998). A new approach to the light/dark test procedure in mice. Pharmacology Biochemistry and Behavior, 60(3), 645-653.

11. Malmberg-Aiello, P., Ipponi, A., Bartolini, A., \& Schunack, W. (2002). Mouse light/dark box test reveals anxiogenic-like effects by activation of histamine H1 receptors. Pharmacology Biochemistry and Behavior, 71(1-2), 313-318.

12. Onasanwo, S., Faborode, S. O., Agrawal, M., Ijiwola, O. L., Jaiyesimi, B. O., \& Narender, T. (2014). Antidepressant and anxiolytic potentials of chebulinic acid in laboratory rodent. Ann Depress Anxiety, 1(7), 1032.

13. Young, R., \& Johnson, D. N. (1991). A fully automated light/dark apparatus useful for comparing anxiolytic agents. Pharmacology Biochemistry and Behavior, 40(4), 739-743.

14. Ahmed N., Rahman M. M., Tareq M. R. H., Ikram M., Alam, S. (2013). CNS depressant and sedative effects of Andrographis paniculata, PhOL. 2:9095.

15. Prut, L., \& Belzung, C. (2003). The open field as a paradigm to measure the effects of drugs on anxiety-like behaviors: a review. European journal of pharmacology, 463(1-3), 3-33.
16. Thakur, V. D., \& Mengi, S. A. (2005). Neuropharmacological profile of Eclipta alba (Linn.) Hassk. Journal of Ethnopharmacology, 102(1), 23-31.

17. Kahnberg, P., Lager E., Rosenberg, C. (2002). Refinement and evaluation of a pharmacophore model for flavone derivatives binding to the benzodiazepine site of the GABAA receptor, Journal of Medicinal Chemistry, 45(19):41884201.

18. Walf, A.A., \& Frye C.A. (2007). The use of the elevated plus maze as an assay of anxiety-related behavior in rodents, Nature Protocols, 2(2):322328.

19. Pellow, S., Chopin, P., File, S. E., \& Briley, M. (1985). Validation of open: closed arm entries in an elevated plus-maze as a measure of anxiety in the rat. Journal of neuroscience methods, 14(3), 149167.

20. Imaizumi, M., Suzuki, T., Machida, H., \& Onodera, K. (1994). A fully automated apparatus for a light/dark test measuring anxiolytic or anxiogenic effects of drugs in mice. Nihon shinkei seishin yakurigaku zasshi= Japanese journal of psychopharmacology, 14(2), 83-91. 